\title{
Research
}

\section{Challenges to the credibility of patient feedback in primary healthcare settings:}

\author{
a qualitative study
}

\begin{abstract}
Background

The UK government has encouraged NHS services to obtain patient feedback to support the further development of patient-centred care. In 2009, the English GP Patient Survey included a sample of 5.5 million, but little is known about its potential utility in informing developments aimed at improving the quality of patients experiences of primary care.
\end{abstract}

\section{Aim}

To investigate primary care providers' response to feedback on patient experience from a national survey.

\section{Design and setting}

Qualitative interview study in 10 genera practices from four primary care trusts in England.

\section{Method}

Semi-structured interviews were conducted with GPs, practice nurses, and practice managers ( $n=37$ ). Transcripts were analysed thematically.

\section{Results}

Although some participants reported making changes to their practice in response to the survey data, many expressed doubts about the credibility of the results. Key issues included: concerns about practical aspects of the survey, such as the response rate and representativeness of the sample; the view that it gave insufficient detail to facilitate change and failed to address some salient issues; and unease about the influence of political influences underpinning its introduction and use.

\section{Conclusion}

Although, in general, primary care professionals have positive attitudes towards patient feedback, this study suggests a mismatch between the conventional demonstration of the objectivity of a questionnaire survey and the attitudes and experiences of those receiving the data. This is likely to prevent doctors from engaging constructively with the survey. These concerns may well militate against the potential of the survey to act as a simple means of capturing, and effectively using, feedback from patients.

\section{Keywords}

primary healthcare; qualitative research reliability and validity; surveys.

\section{INTRODUCTION}

Information obtained through surveys of patients' experiences of primary care is considered to be of importance by the UK Department of Health in informing the design and delivery of primary care services. ${ }^{1}$ In addition, in the UK, patient feedback on individual doctor performance is proposed as a central component in the future processes being developed to regulate doctors. ${ }^{2-4}$ Although guidance has been developed to encourage practitioners to respond positively to such data, $2,5,6$ the resulting information and its potential utility in informing change in doctors' professional practice has not been established.

The recent widespread use of patientexperience surveys in healthcare settings is based on an assumption that feedback has a potentially important role in improving quality of care; some individuals, however, have questioned the basis for such assertions.? Research conducted in healthcare contexts confirms that feedback from patients is not always received positively, and does not automatically result in improvement. ${ }^{8-13} \mathrm{~A}$ recent systematic review of multi-source feedback, which includes patient feedback, concluded that evidence to support the hypothesis that patient feedback has a positive effect on practice change among doctors is inconclusive. ${ }^{14}$ Feedback that

A Asprey, BA, MA, research associate: JL Campbell, MD, FRCGP, professor, Peninsula College of Medicine and Dentistry, University of Exeter, Exeter. J Newbould, BSc, PhD, honorary research fellow, RAND Europe, Cambridge. M Carter, BA, MSc, PG Dip, research associate; A Davey, BSc, MSc, MPhil, research fellow, Peninsula College of Medicine and Dentistry, University of Exeter, Exeter. S Cohn, BA, PhD, Senior Lecturer, Social Science Group; M Roland, DM, professor, Department of Public Health and Primary Care, University of Cambridge, Cambridge. lacks credibility, that contradicts prior knowledge, or that is experienced as a threat at the individual level, is unlikely to be effective. .15-17 $^{17}$ This study was designed to capture the responses of GPs, practice nurses, and practice managers to patient feedback, using the national GP Patient Survey (wnw.gp-patient.co.uk/info/) as an example.

The GP Patient Survey is an anonymous postal survey of randomly selected patients from all English practices. First adopted in 2006, it was extensively revised during the summer of 2008. Responders are asked about the delivery of service in the surgery where they are registered. Prior to its launch, rigorous testing of the survey instrument was undertaken. ${ }^{18}$ Crucially, however, credibility often comprises both objective and subjective components of the believability of a claim or assertion. ${ }^{19}$ As such, although the objective validity and reliability of the survey has been explored using quantitative and qualitative approaches, the subjective component of credibility (that is, the extent to which the resulting data are regarded as sufficiently trusted by recipients in primary care to instigate improvements in servicel has not been explored. Qualitative approaches were, therefore, used to explore the experiences and perceptions of doctors, nurses, and practice managers to capture

\section{Address for correspondence}

John L Campbell, Primary Care Research Group, Peninsula College of Medicine and Dentistry, Magdalen Road, Exeter, EX1 2LU

E-mail: jlcampbellapms.ac.uk

Submitted: 28 May 2012; Editor's response: 26 June 2012; final acceptance: 26 September 2012

\section{CBritish Journal of General Practice}

This is the full-length article (published online 25 Feb 2013) of an abridged version published in print. Cite this article as: Br J Gen Pract 2013; DOI: 10.3399/bjgp13X664252 


\section{How this fits in}

GPs are being encouraged to use patient-experience surveys to inform improvements in quality of care. However, research has indicated that such feedback is unlikely to be effective if it is not perceived to be credible and useful. Although the GP Patient Survey was subjected to rigorous testing in its development, the participants in this study perceived a number of obstacles to the credibility of the data, which could act as a substantial impediment to the survey's constructive use in primary care. The full potential for such surveys to bring about positive change can only be realised if their value is accepted more fully by those working in the primary-care environment.

their views of the 2010 survey, ${ }^{20}$ together with its potential utility.

\section{METHOD}

\section{Participants and setting}

After obtaining ethical approval from Devon and Torbay Research Ethics Committee, practices from four primary care trusts (PCTs) in Bedfordshire, Devon, Plymouth, and Islington were selected to represent a range of geographical areas and GP Patient Survey scores in respect of the question relating to the ease of obtaining an appointment with a doctor. This question was used because it formed the basis of an indicator of primary care performance that was promoted by the UK government as a measure of the accessibility of primary care services; it was also directly related to Quality and Outcome Framework (QOF) payments made to general practices. With the assistance of the local primary care research network, the study approached the five highest scoring and the five lowest scoring practices in each of the four PCTs based on their responses to the ease-ofaccess question in the national survey. As only one high-scoring and one low-scoring practice was required in each $\mathrm{PCT}$, the first practices to respond were recruited into the study. In addition, two low-scoring singlehanded practices were recruited to ensure that this important group of practices were represented in the sample.

\section{Data collection}

Practice managers, practice nurses, and GPs in each practice were invited to take part in individual interviews. These were conducted between June 2010 and June 2011 by experienced, qualitative researchers who had a knowledge of the primary care sector, but were not physicians. After consent was obtained from participants, semi-structured interviews, which included open questions and prompts (see Box 1), were digitally recorded and used to explore participants' experiences and views of the GP Patient Survey. Such an approach offers sufficient flexibility to explore the interviewee's own values and meanings, rather than imposing preconceived structures and assumptions. ${ }^{21}$

Interview schedules were developed within the research team and informed by relevant literature. The topic guide was reviewed after the first few interviews, but, as interviews were semi-structured, steps were taken to ensure that there was always sufficient flexibility to allow interviewees to determine the level of detail provided for particular topics.

\section{Data analysis}

Interviews were transcribed verbatim, fully anonymised, and analysed using NVivo 8.0. Codes were developed iteratively, that is, scripts were continually revisited by members of the team, in light of emerging data, to ensure codes were comprehensively applied. ${ }^{22,23}$ Blind, doublecoding was undertaken on an early sample of transcripts and repeated discussions were held within the research team to ensure consistency and accuracy. Salient themes were identified ${ }^{24,25}$ and checked by several members of the research team to ensure an accurate and balanced interpretation of the data was achieved.

\section{RESULTS}

\section{Sample}

Ten GP practices were recruited and 37 interviews conducted. Four practices with high scores and six lincluding two singlehanded practices) with low scores were recruited. To provide context, the study has included the relevant GP Patient Survey score level following each quotation used in this article.

In each surgery, two GPs lexcept in the two single-handed practices), a practice manager, and one practice nurse were interviewed. The sample comprised 13 males and 24 females. The number of GPs working in the practices varied from one to nine. Five practices were in urban locations, one was on the outskirts of a large city, and four were in small towns whose population varied in size from 6000-23000. The practices also represented a range of social environments, with deprivation scores (based on the Index of Multiple 


\section{Box 1. Ascertaining the views of health professionals and health service managers regarding the GP Patient Survey}

\section{Interview topic guide: GPs}

Interviewer answers any questions and ensures participant has had an opportunity to read the information leaflet and has signed the consent form.

1. 'First of all, I'd like to talk about your views of the GP Patient Survey. I've got a number of things l'd like to ask about, but perhaps you'd like to start off by giving me your own views on the survey.'

If respondent has not heard of the survey provide the following explanation:

The survey asks about a number of areas of importance about how GPs and practices provide care, such as the arrangements for seeing a doctor or nurse, the nature of the interaction between doctor or nurses and patients, or the availability of the doctor.

2. Have you had any dealings with the GP Patient Survey or its results?

3. How do you think this information could best be used to develop care?

4. What is your view of the 'access' questions?

How do you feel about some parts of the survey being linked to the Quality and Outcomes Framework?

5. Do you think the survey should be tied to the finances of your practice?

6. Are you aware of the score of your practice on any particular questions?

Which questions?

Why did you focus on these?

Were there any surprises?

Where did you access this information?

Was the information easy to understand/interpret?

Have you compared these with other practices? If so, which practices, over which questions, and why?

7. Have the scores made you or your colleagues want to change anything?

8. Does your practice plan to share the results with patients? Do you see this as a PCT role?

9. Have any patients mentioned the survey to you; either about completing it or the results?

10. Do you think, over time, the survey might affect your relationship with your patients? If so, in what ways?

What about other colleagues' relationships with patients?

11. Do you think, over time, the survey might affect the way you and your colleagues might do things in your practice? If so, in what ways?

12. What do you think about the survey, in general? What might be its strengths?

And weaknesses?

13. Do you trust the results of the survey?

What does 'trust' mean for you in this context?

14. Can you think of anything else that we have not discussed about this topic, which you would like to raise? most notably due to its scale and central funding, the opportunity to compare results across practices, and the assurance of anonymity and impartiality:

'The advantages of this are that it's anonymous, I guess, and patients can be more honest. Whereas some people may be intimidated [by surveys delivered in the surgery] ... and feel that they would be penalised if they put something unflattering, or that wasn't, you know, to the advantage of the surgery.' (Practice nurse (PN) 401 high score)

Sometimes attitudes were sufficiently positive to have engendered attempts to implement modifications to services, such as changing opening hours or telephone access, and improving communication with patients about the provision of services:

We normally would discuss the GP survey, certainly if we are below the PCT average or if we feel that we haven't really improved or ... we have discussed a lot of times about seeing preferred doctors, speaking over the phone, you know, pre-bookable appointments. We have discussed loads of them and we have come out with action plans and changed our appointments, and... done certain things because of the GP survey really.' (Practice manager (PM) 511 high score)

However, many interviewees had negligible awareness of the GP Patient Survey and more than half (19 out of 37) appeared to confuse it with other surveys at some point during the interview, alluding to data that are not requested in the GP Patient Survey. Many responders were unaware of the rigorous testing prior to its implementation; as such, although some assumed the survey was trustworthy, this sense of trust was frequently not unconditional: the UK national range of deprivation scores is $2.6-68.9 .^{26}$

\section{Attitude to, and awareness of, patient- experience surveys}

Participants were generally in favour of collecting, receiving, and responding to patient feedback. It was frequently acknowledged that patients should have the opportunity to express their views and that providers should listen and make appropriate improvements. The national GP Patient Survey was felt to offer a number of advantages over other similar instruments,
I suppose I would trust it to the extent that I take some notice of what the results are, but also with a degree of scepticism, because I understand that it's a much more complex matter than it appears there [in the GP Patient Survey results].' (GP 308 high score)

\section{Perceived credibility of survey results}

There was evidence that acceptance of the survey data as sufficiently credible to be used to improve services was seriously impeded by a number of perceived obstacles; this was the case for practices 


\section{Table 1. Perceived challenges to credibility of feedback from the GP Patient Survey}

\begin{tabular}{|c|c|}
\hline General challenge & Specific issues \\
\hline \multicolumn{2}{|l|}{ Practical aspects of the survey } \\
\hline Responders are not representative & $\begin{array}{l}\text { Over-representation of infrequent attenders and } \\
\text { people with extreme views; under-representation of } \\
\text { those with literacy/language difficulties, older people, } \\
\text { single parents, and busy working adults }\end{array}$ \\
\hline Hidden assumptions & $\begin{array}{l}\text { Questions on care planning and shared decision } \\
\text { making assume that all patients want written } \\
\text { documents about their treatment and involvement in } \\
\text { their own care }\end{array}$ \\
\hline Order of questions & $\begin{array}{l}\text { Important questions about consultations occur too } \\
\text { late in the questionnaire, when the responder's } \\
\text { concentration may be reduced }\end{array}$ \\
\hline Important questions missing & $\begin{array}{l}\text { No questions about whether patients understand } \\
\text { their medical condition, side-effects of drugs, options } \\
\text { open to them, and long-term consequences }\end{array}$ \\
\hline Low response rate & Not a 'fair reflection' of all patients \\
\hline Questionnaire is too long & $\begin{array}{l}\text { Systematic exclusion of certain groups with less time } \\
\text { on their hands }\end{array}$ \\
\hline Leading questions & $\begin{array}{l}\text { These create artificially low scores, especially about } \\
\text { surgery opening times }\end{array}$ \\
\hline \multicolumn{2}{|l|}{ Interpretation of scores } \\
\hline Contradictory scores & $\begin{array}{l}\text { Questions about immediate access/seeing a preferred } \\
\text { doctor deal with conflicting elements of care; it is } \\
\text { difficult for a practice to score well on both }\end{array}$ \\
\hline Unclear meaning of scores & $\begin{array}{l}\text { High scores for low waiting times may not indicate } \\
\text { good-quality service; giving patients more time may } \\
\text { indicate more successful care }\end{array}$ \\
\hline Limitation of numerical data & $\begin{array}{l}\text { Numerical data alone is insufficient or even } \\
\text { misleading, as the context of responses is unclear. } \\
\text { Has limited potential to inform improvements }\end{array}$ \\
\hline Individual feedback & $\begin{array}{l}\text { Feedback is at practice level and gives no indication } \\
\text { about individual practitioners. It is, therefore, difficult } \\
\text { to identify areas for improvement }\end{array}$ \\
\hline Confounding factors & $\begin{array}{l}\text { Results are presented out of context, ignoring level } \\
\text { of affluence or deprivation, cultural differences in } \\
\text { patients' expectations, incidence of chronic disease, } \\
\text { staff illness, size of practice, number of part-time staff }\end{array}$ \\
\hline No new information & $\begin{array}{l}\text { The survey does not provide information that is not } \\
\text { already known through patients' comments, in-house } \\
\text { surveys, or formal complaints }\end{array}$ \\
\hline \multicolumn{2}{|l|}{ Political influences } \\
\hline Survey is a political tool & $\begin{array}{l}\text { Patient-experience surveys are a political tool } \\
\text { designed for political purposes }\end{array}$ \\
\hline Political motives introduce bias & $\begin{array}{l}\text { Content of the questionnaire is influenced by political } \\
\text { aims, some important questions may be overlooked }\end{array}$ \\
\hline $\begin{array}{l}\text { Link between GP Patient Survey and } \\
\text { QOF payments is unacceptable }\end{array}$ & $\begin{array}{l}\text { Basing pay for performance on patient surveys is } \\
\text { punitive and unjust }\end{array}$ \\
\hline Patients have unrealistic expectations & $\begin{array}{l}\text { Successive governments have misled patients into } \\
\text { having unrealistic expectations of primary care, but } \\
\text { additional funding has not been provided }\end{array}$ \\
\hline $\begin{array}{l}\text { Improving services does not lead to } \\
\text { improved scores }\end{array}$ & $\begin{array}{l}\text { Attempts to improve services made in response to the } \\
\text { survey have not improved scores, casting doubt on the } \\
\text { credibility of the survey }\end{array}$ \\
\hline
\end{tabular}

QOF = Quality and Outcomes Framework with both high and low scores. A range of concerns was reported (summarised in Table 1), with some small differences between the groups: for example, practice nurses, on the whole, expressed fewer reservations about the survey data than GPs, although this may have simply been because nurses were less aware of the survey and less familiar with the results. Overall, however, the same primary issues were raised by all groups, and there was not sufficient variation to make inferences about differences between the professional groups with any confidence. Participants expressed concerns about three main areas:

- practical aspects;

- interpretation of the scores; and

- possible political dimensions of the GP Patient Survey.

\section{Practical aspects of the survey}

Representativeness of the sample. Although interviewees were confident that the survey was sent to a random sample of patients, they were concerned that those who replied were unlikely to be representative of their practice population. There was a widespread view that respondents would tend to be among a 'vocal minority', with largely negative views:

My own feeling is that in these patient surveys, people will tend to highlight negative aspects of their treatment, or their appointment system, rather than positive. So, in that way, it might be a bit skewed and, therefore, not really fair.' (PM 514 high scorel

There were also concerns that certain types or groups of people would not be represented, such as those with mental health problems, those with literacy difficulties, and those for whom English was a second language. Others were concerned that certain age groups or patients with specific lifestyles would be unlikely to respond:

So I think a lot of working professionals and working people will go out a bit ... Singleparent mums probably won't have time to do it and obviously the very ill probably wouldn't. If you're above 70, you probably won't have the concentration and you won't feel well enough to do such surveys ... So it leaves that very small percentage I feel. I might be totally wrong, but that's my perception.' (GP 316 low score) 
In contrast, however, some participants expressed concerns that other groups of patients might be over-represented. As the survey was administered by post, there were worries that those who rarely attended the surgery were included, whose perceptions were potentially inaccurate:

I think the most frustrating thing about the GP survey is that it goes out to people that wouldn't necessarily access the practice for years, so we may do this, that, and the other over the years that we have implemented, but because they haven't been seen in the last 4 years, they have no idea.' (PM 511 high score)

The design of the survey questionnaire. Doubts were also raised about the nature of the questions asked in the survey. Specific questions were thought to be flawed, based on an incorrect assumption that particular aspects of care are invariably and universally valued by patients. In relation to involving patients in decisions about their care, one GP noted:

Actually there's a burdening around the word "good", [as] a lot of patients would regard it as bad, being involved in their care ... And then there are other social classes ... or people, possibly, who are more experienced service users, who regard it as good ... The meaning of [a] "good" and "bad" score is too simple in the context of this question.' (GP 309 low score)

Likewise, it was felt by some responders that assumptions were made about care plans:

'Things like written documents, an awful lot of people don't particularly want a written document really. The assumption in here is that everybody wants to have a written document ... It's appropriate for some people and not others.' (PN 402 low score)

Some responders were dissatisfied with the order of the questions. For example, domains perceived as particularly important (such as those concerning the quality of consultations) were felt to occur too late in the questionnaire, when the responder might already be tired of the process, thereby potentially reducing the quality of the data. Others felt that these important issues were not addressed adequately and wanted more questions relating to consultations.

\section{Interpretation of scores}

It was felt that some questions yielded scores that were an inadequate measure of the quality of care received. For example, a high score on the questions about rapid access to appointments might only be achieved at the expense of continuity, which some regarded as a better indicator of high-quality care:

"I think things have probably been coloured by the culture of "book on the day" that we, like many practices, went for several years ago. But we've realised that continuity of care is very important and now we're doing all we can to say "find the doctor, stick with them, and you can book up to 2 weeks in advance.' (GP 307 high score)

Similarly, responders noted that a positive score on the questions about waiting times might indicate that patients were being rushed through appointments, thereby not capturing the importance attributed by practices to ensuring patients were given adequate time and attention.

The value of the exclusively quantitative GP Patient Survey data was also questioned. It was felt that, as patients were not able to write comments, there was insufficient information for making improvements:

'Yeah, I think sometimes tick boxes, they're okay and they stop them [patients] from waffling but they don't also give the patient's point of view.' (PN 406 high score)

Another objection that was frequently raised was the lack of feedback on individual practitioners, which resulted in less meaningful and useful data:

'It's hard to know who it is about... when the feedback comes back about general consultation style / kind of think. "Well there's nothing I can do about that because I think my own style is okay," so I don't know whether the data is inaccurate or whether it's a reflection of what some of my colleagues are doing but, actually, I can't change what my colleagues do in that respect.' (GP 317 low score)

The presentation of the results of the survey was also seen as a threat to credibility, as results were presented without context, ignoring possible confounding factors. For example, in areas where there was a high demand for consultations, either due to high levels of deprivation and associated social problems and/or high prevalence of disease, this 
inevitably resulted in less easy access to appointments and often poor scores:

'The waiting times can be long because we do have a high amount of prevalence ... If you've got a practice, which has a high proportion of worried well and a very high prevalence of disease ... that takes time, that takes appointments, that means that we're busier than perhaps some of the other practices. And if you're busier, that means it's going to be harder for people to get in.' (GP 304 low score)

We have this huge sink of morbidity in our practice, and we could offer four times the number of surgeries and still be busy. That's the reality ... Our demand for doctors time is very high and we have to manage that, and that means people can't get appointments as much as they would like to.' (GP 302 high score)

On the other hand, in more affluent areas, a number of factors reduced the pressure for appointments:

... in my previous training practice in Hampstead, they had an extremely low referral rate because everyone is going private, all their medications are done privately and most of your patients are abroad, you know, so your appointment system is great because, you know, a third of your population is American, who are in America ... So, you know, how can you say they are better doctors or a better practice than the one in East London?' (GP 316 low score)

It was also felt that large practices with many part-time doctors were disadvantaged, as it was more difficult to achieve continuity and obtain patients' loyalty:

'There's lots of doctors here, a lot of them are part-time, a lot of them do other things so ... the fact that we're not a small practice with one or two doctors, you're not going to see who you want and you're not going to have your following of patients that are very loyal to the practice.' (GP 315 low score)

It was, therefore, felt that the context of primary care was not a 'level playing field' and so could not be captured by simple scores.

\section{Political influences}

The most emotive responses given in the interviews concerned a suspicion that such surveys were driven by political motives, primarily geared towards cutting NHS costs:

We just feel the way they ask the questions is stacked against US, and I think most GPS have a cynical view of that.' (GP 311 low score)

'The sceptic in me feels that this is a costcutting exercise and little to do with a real commitment to patient satisfaction or to help those in primary care deliver a better service.' (PN 402 low score)

At the time of data collection, the GP Patient Survey's 'access' questions were related to QOF payments made to general practices. In surgeries with low scores, whose payments were consequently adversely affected, individuals more often conveyed a strong sense of individual threat, sometimes expressing a wholesale rejection of the survey results:

Because actually there is no logic in it apart from the fact that the government want my money ... I'm totally cynical about the government's motivation and this is just part of that ... It's part of their punishment system. So if they think that they've got me over a barrel, forget it, because they haven't. And I can just happily carry on and ignore this survey.' (GP 303 low score)

This sense of demoralisation, however, was not exclusively related to financial consequences, but also concerned with the public availability of the results:

'Obviously from a QOF perspective there's a financial element, we like to maintain a high income, of course we do, but I don't think in this particular instance it's paramount, it's just it's more of the ... almost the shame factor ... Information is shared so much. you don't want to see yourself on a pie chart or on a bar chart as bottom of the pile.' (PM 512 low score)

In support of this, even within practices that had obtained high scores, there was a general suspicion that the survey was driven by political motives and not the desire to improve the quality of care:

"I think one weakness was ... it was seen as a way of softening up primary care for extended hours, by showing there was a demand out there for it ... and by opening the doors wider and wider, then we'll be dealing with more and more trivial things 
... I don't think there's going to be huge clinical gains from doing that.' (GP 307 high score)

Political motives were also felt to introduce an element of bias to the survey, that is, only those questions asked would be seen as significant and other important questions would not be brought into the public domain:

'It's a bit of, of tail and dog isn't it? ... Because it has been measured, is it necessarily important? It's important but is it as important as some of the things that haven't been measured?' (GP 309 low score)

Low scores were also felt to derive from the influence of government rhetoric, which participants felt had raised patients' expectations unrealistically without providing additional funding for services. It was also felt that expectations had been raised by government's emphasis on rapid access, fostering an over-reliance on medical help and resulting in an unreasonable demand for appointments:

I suppose what I feel is that instant, easy access is not necessarily the best thing ... It's all being touted as that's what you should be able to do, but actually it kind of makes people less self-sufficient, more doctor-dependent, it squeezes out the people who do need to be seen ...' (GP 308 high score)

As a result of these feelings, interviewees in high-scoring practices, although less concerned about survey results, were as discouraged as their low-scoring counterparts, when scores appeared resistant to change after local improvements had been made:

'Though, you know, you get despondent I suppose. For example, with hours, we went in to extend them and satisfaction with opening hours has steadily gone down. So you think okay ... this isn't very encouraging... We make things better and the survey shows deterioration.' (GP 314 high score)

'Our survey was actually lower, we got less points this year than the year before. And yet we've put in an awful lot of effort to get that access up and to inform patients, and yet it's come back worse. And we're just thinking "Well, why?" You know, what else can we do?' (PM 502 low score)

\section{DISCUSSION}

\section{Summary}

In this study, patient-experience feedback was acknowledged to be a valuable source of information that could contribute to the implementation of appropriate, positive change. However, the acceptance of data from the GP Patient Survey was hindered by a number of perceived barriers to the credibility of the survey. It might be assumed that such perceived obstacles were merely a post-hoc rationalisation, expressed by those working in low-scoring practices, who potentially experienced negative financial consequences as a result of some performance payments being related to survey scores. However, the examples given in this article, drawn from practices with a wide range of GP Patient Survey scores, demonstrate that mistrust of the data was commonplace.

A number of aspects of the survey were questioned, such as the representativeness of the responders, the low response rate, the length of the questionnaire, the order and framing of the questions, and the issues selected for measurement. It was also felt that there were implicit assumptions underlying some questions that might not reflect patients' true expectations or needs. The exclusively quantitative data and the lack of individualised feedback were seen as limiting the potential to improve practice. The lack of attention to confounding factors, such as levels of deprivation or affluence, cast further doubt on the published results. Credibility was also seriously undermined by perceived political influences, both in terms of raising unrealistic expectations in patients and in manipulating the content of the survey, which was believed by a number of responders, ultimately, to be serving political ends.

\section{Strengths and limitations}

This research provides insight into the way a national survey of patient experience is received within primary care settings. The GP Patient Survey is a major national UK survey with a response rate $(38 \%)$ that is comparable to similar surveys undertaken elsewhere in the world. ${ }^{27}$ The lack of significant non-response bias in respect of some key measures in the survey has been reported previously. ${ }^{28}$

This sample included a range of general practices in terms of demographic profile, geographic location, size, and GP Patient Survey scores. The study believes that a comprehensive range of attitudes was revealed, using in-depth interviews undertaken not only with GPs, but also with 
practice nurses and practice managers The researchers had extensive experience of qualitative research in the health service and the resulting data were analysed systematically, iteratively, and in detail.

A systematic exploration of how survey data had been used within general practice was not undertaken, although participants were asked to give a general indication of this. Another limitation was imposed by the primary focus on the impact of one particular survey, rather than other instruments that may generate different attitudes and experiences.

\section{Comparison with existing literature}

There is a growing body of national and international research conducted in healthcare contexts investigating the effect of feedback on professional practice, which confirms that this is not always a positive experience or one that automatically results in service improvement. ${ }^{9-13}$ It has also been suggested that if feedback elicits a negative response in doctors, it may be detrimental to their future performance..$^{8,15-17}$ The current research highlights a mismatch between the conventional demonstration of the 'objectivity' of a survey tool, and the doubts and questions raised by those receiving the data, which prevented wholesale acceptance of its results. As rigorous pilot testing alone did not automatically translate into the results being trusted enough to be acted upon, the ability of the survey to bring about positive change seemed likely to be limited.

\section{Implications for practice}

Since this study was undertaken, the UK government has stopped using GP Patient Survey data as the basis of a pay-forperformance scheme in respect of access to primary care services. This may improve acceptability of these data in primary care, although doubts and objections in this study were not solely raised by low scorers, some of whom felt penalised financially by the survey results.

In the UK, the most recent iteration of the NHS contract for GPs promotes the use of parallel local surveys. Under 'direct enhanced service' arrangements, GPs are being given a financial incentive to develop such surveys with patient-reference groups and to discuss the results with them as a means of obtaining greater engagement with patients. ${ }^{29,30}$ This new approach may result in a less-critical attitude to survey results; in addition, engaging professional and managerial stakeholders at an earlier stage is likely to be beneficial, as results are only useful if they are accepted as credible and appropriate by those for whom they are intended.

Key to the success of this new initiative may well be the sense of a shift from a centralised directive to more localised responsibility, and from practice-level to individualised feedback for GPs. Although a number of participants favoured local, rather than national surveys, a locally driven approach with non-standardised methodology will limit the ability of surveys to be used to compare practices. Problematic issues may relate to sampling bias, benchmarking, and comparability of data, and the possibility of gaming in locally administered surveys. Nevertheless, responding to the issues documented in this research may help inform the design of more acceptable and effective ways of capturing and responding to the patient voice in ways that will be capable of informing constructive change in general practice.

\section{Competing interests}

John Campbell and Martin Roland act as academic advisors to Ipsos MORI in the development and validation of the GP Patient Survey; both the University of Exeter and the University of Cambridge have received payment for this. All other authors have declared no competing interests.

\section{Acknowledgements}

The authors gratefully acknowledge the support of the participating practices in facilitating this research and would like to thank the Department of Health for funding this study.

\section{Discuss this article}

Contribute and read comments about this article on the Discussion Forum: http://www.rcgp.org.uk/bjgp-discuss 


\section{REFERENCES}

1. Department of Health. Equity and excellence: liberating the NHS. London: Department of Health, 2010. http://www.dh.gov.uk/prod_consum_dh/groups/ dh_digitalassets/dadh/Qden/daps/documents/digitalasset/dh_117794.pdf laccessed 8 Jan 2013).

2. Department of Health. Understanding what matters: a guide to using patient feedback to transform services. London: Department of Health, 2009. http:// www.dh.gov.uk/prod_consum_dh/groups/dh_digitalassets/documents/ digitalasset/dh_099779.pdf (accessed 8 Jan 2013).

3. Chief Medical Officer for England's Working Group. Medical revalidation Principles and Next Steps. London: Department of Health, 2008. http://umw. dh.gov.uk/prod_consum_dh/groups/dh_digitalassets/dadh/den/documents/ digitalasset/dh_086431.pdf (accessed 8 Jan 2013).

4. Campbell JL, Richards SH, Dickens A, et al. Assessing the professional performance of UK doctors: an evaluation of the utility of the General Medical Council patient and colleague questionnaires. Qual Saf Health Care 2008; 17(3): 187-193.

5. British Medical Association. Developing general practice: listening to patients. London: BMA, 2009.

6. Carter M, Roland M, Campbell J, Brearley S. Using the GP patient survey to improve patient care: a guide for general practices. National Primary Care Research and Development Centre, 2009. http://www.medicine.manchester. ac.uk/primarycare/npcrdc-archive/Publications/PSHandbook.Web.pdf laccessed 8 Jan 2013).

7. Fung $\mathrm{CH}$, Lim YW, Mattke S, et al. Systematic review: the evidence that publishing patient care performance data improves quality of care. Ann Intern Med 2008; 148(2): 111-123.

8. Edwards A, Evans R, White P. Elmyn G. Experiencing patient-experience surveys: a qualitative study of the accounts of GPs. Br J Gen Pract 2011; DOI: 10.3399/ bjgp11X567072.

9. Cheraghi-Sohi S, Bower P. Can the feedback of patient assessments, brief training, or their combination, improve the interpersonal skills of primary care physicians? A systematic review. BMC Health Serv Res 2008; 8: 179.

10. Reinders ME, Ryan BL, Blankenstein AH, et al. The effect of patient feedback on physicians' consultation skills: a systematic review. Acad Med 2011; 86(11): 1426-1436.

11. Friedberg MW, SteelFish GK, Karp M, et al. Physician groups' use of data from patient experience surveys. J Gen Intern Med 2011; 26(5): 498-504.

12. Reeves R, Seccombe I. Do patient surveys work? The influence of a national survey programme on local quality-improvement initiatives. Qual Saf Health Care 2008; 17(6): 437-441.

13. Heje HN, Vedsted P, Olesen F. General practitioners' experience and benefits from patient evaluations. BMC Fam Pract 2011; 12: 116.

14. Miller A, Archer J. Impact of workplace assessment on doctors' education and performance: a systematic review. BMJ 2010; 341(7775): c5064.
15. Sargeant J, Mann K, Ferrier S. Exploring family physicians' reactions to multisource feedback: perceptions of credibility and usefulness. Med Educ 2005 39(5): 497-504.

16. Sargeant J, Mann K, Sinclair D, et al. Understanding the influence of emotions and reflection upon multi-source feedback acceptance and use. Adv Health Sci Educ Theory Pract 2008; 13(3): 275-288.

17. Sargeant JM, Mann KV, van der Vleuten CP, Metsemakers JF. Reflection: a link between receiving and using assessment feedback. Adv Health Sci Educ Theory Pract 2009; 14(3): 399-410

18. Department of Health. Ipsos Mori Technical Annex for the General Practice Patient Survey: 2009/2010 Annual Report. London: Department of Health, 2010. http://www.gp-patient.co.uk/results/download/y4q4/y4q4_AnnualTechnical_ unweighted.pdf (accessed 8 Jan 2013).

19. Flanagin AJ, Metzger MJ. Digital media and youth: unparalleled opportunity and unprecedented responsibility. In: Metzger MJ, Flanagin AJ (eds.). Digital media, youth and credibility. Massachusetts: MIT Press, 2008: 5-28.

20. GPPS. Questionnaires and letters. Year 4 Questionnaire 1. http://wnw. gp-patient.co.uk/questionnaires/ laccessed 8 Jan 2013).

21. Britten N. Qualitative research: qualitative interviews in medical research. BMJ 1995; 311(6999): 251-253.

22. Pope C, Ziebland S, Mays N. Qualitative research in health care. Analysing qualitative data. BMJ 2000; 320(7227): 114-116.

23. Lofland J, Lofland L. Analyzing social settings: a guide to qualitative observation and analysis. Belmont: Wadworth, 1995.

24. Braun V, Clarke V. Using thematic analysis in psychology. Qual Res Psychol 2006; 3(2): 77-101

25. Ritchie J. The Applications of Qualitative Methods to Social Research. In: Ritchie J, Lewis J (eds.). Qualitative research practice: a guide for social science students and researchers. London: Sage Publications, 2003: 24-46.

26. Association of Public Health Observatories. APHO national general practice profiles. http://www.apho.org.uk/pracprof laccessed 8 Jan 2013).

27. Elliott MN, Edwards C, Angeles J, et al. Patterns of unit and item nonresponse in the CAHPS Hospital Survey. Health Serv Res 2005; 40(6 Pt 2): 2096-2119.

28. Lyratzopoulos G, Elliott MN, Barbiere JM, et al. How can health care organizations be reliably compared?: Lessons from a national survey of patient experience. Med Care 2011; 49(8): 724-733.

29. Department of Health. The functions of GP Commissioning consortia: a working document. London: Department of Health, 2011. http://www.dh.gov.uk/ prod_consum_dh/groups/dh_digitalassets/documents/digitalasset/dh_125006. pdf (accessed 8 Jan 2013).

30. British Medical Association. Patient participation directed enhanced service (DES) for GMS contract. London: BMA, 2011. http://www.nhsemployers.org/ Aboutus/Publications/Pages/Patient-participation-enhanced-service.aspx laccessed 8 Jan 2013) 